\title{
Association of ABO Blood Group and Malaria Parasitic Infection in Eiedbabkier, Sudan
}

\author{
Sara Muawia ${ }^{1}$,Mahdi H. A. Abdalla ${ }^{2 *}$ \\ ${ }^{I}$ Department Of Hematology, Faculty ofMedical Laboratory Sciences, Al-Neelain University, \\ Khartoum, Sudan. \\ ${ }^{2}$ Associate Professor ofHematology, Department ofHematology, Faculty Of Medical Laboratory \\ Sciences, Omdurman Ahlia University, Khartoum, Sudan. \\ *Corresponding author:Mahdi H. A. Abdalla,mahdi_razig@hotmail.com
}

\begin{abstract}
:
Background:Malaria is an infection caused by protozoan parasites of the genus Plasmodium, and transmitted by the bite of infected Anopheles mosquitoes. Many studies reported an association between malaria and parasitic density with a different $A B O$ blood group, but with contradictory results.

Objective:The purpose of this study was to determine the association between ABO blood groups and Malaria parasiticinfection.

Methods:Two hundred and six samples from Sudanese population were included in this study (103 of them were Malaria patients and the other 103 were healthy controls), all of them were evaluated to determine the ABO blood groups. The blood group of the study participants was determined by direct ABO method.

Results: in our study there was asignificant association between the ABO blood group and malaria infection with ( $p$ value 0.013$)$. The most frequent blood group among patient group was $A(42,40.8 \%)$, followed by $O$ $(28,27.2 \%), B(26,25.2 \%)$, and at last $A B(7,6.8 \%)$.

Conclusion:The current study revealed that most frequent blood group in patient group was $A$, followed by $O$, $B$, and eventually $A B$, the males were more affected by malaria than females and blood group $B$ is more susceptible to the infection by malaria than other blood groups.
\end{abstract}

Keywords:Malaria, ABO Blood Group, Sudan.

\section{Introduction}

Malaria is an infection caused by intracellularprotozoan parasites of the genus Plasmodium and transmitted by the bite of infected Anopheles mosquitoes. Out of the four species that infect humans, Plasmodium falciparum is the principal cause of severe clinical manifestations. ${ }^{[1]}$ As perthe latest WHO data, there were about 214 million cases of malaria and438000 people died of malaria in 2015, with over $90 \%$ of these deaths occurring in Africa. ${ }^{[2]}$ Sudan is one of these African countries suffering from this epidemicdisease burden, and EiedBabkieris located in east of Khartoum town.In Khartoum State, it is estimated that an average of 300000 malaria cases and 500 deaths occurred annually. ${ }^{[3,4]}$ This is mainly due to the high temperatures and inadequate infrastructure regarding drainage system leading to stagnation of waterto becomes breeding ground for mosquitoes especially in rainfall season.

The ABO blood groups consist of $\mathrm{A}, \mathrm{B}$ and $\mathrm{H}$ antigens which regulate the protein activities during infection. ${ }^{[5]}$ In clinical practice, $\mathrm{ABO}$ is the most important system for blood group compatibility. Since their discovery, $\mathrm{ABO}$ antigen associations with infections and other diseases have been the subject of hundreds of publications. ${ }^{[6,7]}$ Several studies were conducted to investigate the association between ABO blood group system and some disease conditions. ${ }^{[8]}$

A and B blood group antigens are trisaccharidesbound to a variety of glycoproteins and glycolipids on the surface of red blood cells, and these trisaccharides are thought to act as receptors for rosetting on uninfected red blood cells and bind to parasite rosetting ligands such as PfEMP-1 and sequestrin However, blood group antigens $\mathrm{A}$ and $\mathrm{B}$ are not expressed in blood group $\mathrm{O}$ individuals. As a result, rosettes formed by blood group $\mathrm{O}$ are suggested to be smaller and easily disrupted than rosettes formed by blood group A, B or AB red blood cells.

In view of a heavy burden placed on human health due to malaria, many investigations have been conducted to find out whether or not ABO blood groups antigens are associated with susceptibility, resistance, or severity of P.falciparum malaria. Nonetheless, these studies have reported contradictory results. Some studies reported the absence of significant association between $\mathrm{P}$. falciparum (prevalence, parasitaemia or antibody titer) and ABO antigens. ${ }^{[9]}$ On the other hand, some studies have shown that high frequency of malaria episodes has been observed among blood group A individuals as compared with other blood groups individuals. ${ }^{[10,11]}$ Furthermore, Migot-Nabias and thirana et al observed low parasitaemia and uncomplicated malaria cases among blood group ' $\mathrm{O}$ ' individuals. ${ }^{[12]}$ 
In view of a heavy burden placed on human health due to malaria, a good many investigations have been conducted to find out whether ABO blood groups antigens are associated with susceptibility, resistance, or severity of malaria. Much new information has emerged since a relationship between ABO and malaria was first suggested $\geq 40$ years ago. ${ }^{[13]}$ Many other coexisting factors made the study of relationshipbetween malaria and $\mathrm{ABO} / \mathrm{Rh}$ blood groups difficult that varying findings are reported.

However, the correlation of severity of malarial infection to the patient's blood group has been of recent interest in the quest for the answers to the factors influencing clinical course of the disease. In view of this, the main aim of this study was to determine if there is association between ABO blood groups and malaria parasite infection among the population of EiedBabkier, Khartoum state,Sudan.

\section{Materials and Methods}

This is a case-control study, conducted in EidBabiker, Khartoum state- Sudan, during the period of September to December 2016. All Participants are Sudanese, males and females (N/206), were divided into two groups; patient group (N/103), known as cases were malaria patients.Diagnosed by using blood film for malaria and immunochromatography test (ICT). Control group known as healthy subjects group, not suffering from malaria (N/103). After signing an informed consent, the demographic and clinical data was taken from the participants (case and control), and recorded in a pre-designed questionnaire. Then $5 \mathrm{ml}$ of venous blood was collected from case and control group, inEDTA-K3 blood containers, under septic condition, mixed gently for the determination of direct ABOblood grouping, usingSpectrum antisera-Egypt. Ethical clearance was obtained from ethical committee, ministry of health-Sudan, and informed consent was obtained from each participant before sample collection.

Statistical analysis was performed using statistical package for social science (SPSS) software. Evaluation of patient's quantitative data was performed using the t-test. Comparison of frequency distribution between groups was made by the $\mathrm{X}^{2}$ test. All tests are two-sided and Pvalue less than 0.05 have been considered as statistically significant.

\section{Results}

Descriptive statistics of quantitative variable (mean \pm SD) showed that the mean age among patients was $(22.93 \pm 15.7)$ which was insignificantly greater than among female $(24 \pm 16.3)$ (P-value 0.360). Males were significantly more affected by malaria $(61,59.2 \%)$ than females $(42,40.8 \%)$ (P-value 0.002$)$, and the OR of Male/female (2.4), which means, the chance of malaria infection among males was 2.4 times female. The most frequent blood group in patients group was:A (42, 40.8\%), followed by O $(28,27.2 \%), \mathrm{B}(26,25.2 \%)$, and at last $\mathrm{AB}(7,6.8 \%)$, while most frequent blood group in patient group was: $\mathrm{O}(45,43.7 \%)$, followed by $\mathrm{A}(30$, $29.1 \%), \mathrm{B}(19,18.4 \%)$, and at last AB $(9,8.7 \%)$. Malaria infection showed significant association with blood types ( $\mathrm{P}$ value 0.013, OR 2.07), the proportion of non-O (A, B and $\mathrm{AB}$ ) phenotypes was higher in malaria patients compared with non-infected individuals. (TABLE 1). There was no significant association between species of malaria parasite within different blood groups. (P value 0.567) (TABLE 2). Table 3 shows the distribution of $\mathrm{ABO}$ blood groups per density of malaria parasites.

Table 1. Associationof blood groups and malaria infection

\begin{tabular}{|c|c|c|c|c|}
\hline & & Count & Column N \% & Odd Ratios \\
\hline \multirow{2}{*}{ Group A } & Not A & 134 & $65.0 \%$ & \multirow[t]{2}{*}{$\mathrm{A} / \mathrm{Not} \mathrm{A}=1.16$} \\
\hline & $\mathrm{A}$ & 72 & $35.0 \%$ & \\
\hline \multirow{2}{*}{ Group B } & Not B & 161 & $78.2 \%$ & \multirow[t]{2}{*}{$\mathrm{B} / \mathrm{Not} \mathrm{B}=1.49$} \\
\hline & $\mathrm{B}$ & 45 & $21.8 \%$ & \\
\hline \multirow{2}{*}{ Group AB } & Not $A B$ & 190 & $92.2 \%$ & \multirow[t]{2}{*}{$\mathrm{AB} / \mathrm{Not} \mathrm{AB}=.761$} \\
\hline & $\mathrm{AB}$ & 16 & $7.8 \%$ & \\
\hline \multirow{2}{*}{ Group $O$} & Not $\mathrm{O}$ & 133 & $64.6 \%$ & \multirow[t]{2}{*}{ Not $\mathrm{O} / \mathrm{O}=2.07$} \\
\hline & $\mathrm{O}$ & 73 & $35.4 \%$ & \\
\hline
\end{tabular}

Table 2. The association between species of malaria parasite within different blood groups.

\begin{tabular}{|c|c|c|c|c|c|c|}
\hline & \multicolumn{5}{|c|}{ Type of Malaria } \\
\hline & & \multicolumn{2}{|c|}{ Falciparum } & \multicolumn{3}{|c|}{$\begin{array}{r}\text { Vivax } \\
\end{array}$} \\
\hline & & Count & Row N \% & Count & Row N \% & P-value \\
\hline \multirow{4}{*}{ Blood group } & A & 31 & $73.8 \%$ & 11 & $26.2 \%$ & \multirow{4}{*}{0.567} \\
\hline & $\mathrm{B}$ & 16 & $61.5 \%$ & 10 & $38.5 \%$ & \\
\hline & $\mathrm{AB}$ & 6 & $85.7 \%$ & 1 & $14.3 \%$ & \\
\hline & $\mathrm{O}$ & 20 & $71.4 \%$ & 8 & $28.6 \%$ & \\
\hline Total & & 73 & & 30 & & \\
\hline
\end{tabular}


Table 3. The association between density of malaria parasite and blood groups.

\begin{tabular}{|c|c|c|c|c|c|c|c|c|}
\hline & \multicolumn{7}{|c|}{ Density } \\
\hline & & \multicolumn{2}{|c|}{+} & \multicolumn{2}{|c|}{++} & \multicolumn{3}{|c|}{+++} \\
\hline & & Count & Row N \% & Count & Row N \% & Count & Row N \% & P-value \\
\hline \multirow{4}{*}{ Blood group } & $\mathrm{A}$ & 30 & $71.4 \%$ & 9 & $21.4 \%$ & 3 & $7.1 \%$ & \multirow{4}{*}{0.513} \\
\hline & $\mathrm{B}$ & 18 & $69.2 \%$ & 6 & $23.1 \%$ & 2 & $7.7 \%$ & \\
\hline & $\mathrm{AB}$ & 3 & $42.9 \%$ & 4 & $57.1 \%$ & 0 & $0.0 \%$ & \\
\hline & $\mathrm{O}$ & 16 & $57.1 \%$ & 9 & $32.1 \%$ & 3 & $10.7 \%$ & \\
\hline
\end{tabular}

\section{Discussion}

The role of $\mathrm{ABO}$ blood group in malaria has been investigated in various populations, but with contradictory reports. This study was designed to evaluate the association of ABO blood group and malaria parasitic infection in patients of EiedBabkier, Sudan. To achieve this aim, 103 patient's samples and 103 controls were analyzed.

Our study demonstrated that themost frequent blood group in patients was A (40.8\%) phenotype followed by $\mathrm{O}(27.2 \%), \mathrm{B}(25.2 \%)$, and $\mathrm{AB}(6.8 \%)$, with higher proportion of non-O phenotypes malaria patients compared with non-infected individuals. The chance of havingmalaria infection in individuals with non- $\mathrm{O}$ blood groups was two times more than individuals showing blood $\mathrm{O}$ phenotypes $(\mathrm{OR}=2.07)$, this is consistent with previous reports ${ }^{[14,15]}$, suggesting that individuals with blood groups $\mathrm{A}, \mathrm{B}$ and $\mathrm{AB}$ are more susceptible to $\mathrm{P}$. falciparum infection than those with $\mathrm{O}$ group.Our study contradicts with some other studies.Zerihun T. et al reported high frequencies of O blood group (51.3\%) followed by A (23.5\%), B (21.6\%), and $\mathrm{AB}(3.3 \%)^{[16]}$. Singh et al.have reported that ' $\mathrm{A}$ ', ' $\mathrm{B}$ ' and ' $\mathrm{O}$ ' groups are equally susceptible to malaria while 'AB' is less susceptible ${ }^{[17]}$.

Parasitaemia seemed to be relatively high across all blood groups with groups A apparently recording the highest parasitic density. Hence, results of the current study suggest that patients with blood group 'A' have increased risk of developing severe infection

The rate of malaria infection was higher among males $(59.2 \%)$ than females $(40.8 \%)$. The finding in this study is consistent with previous study done by Bonilla and Rodriguez ${ }^{[18]}$, where males had a higher malaria parasite infection rate than females. The presents study was, however, in contrast to that of Vlassoff and Bonilla $^{[19]}$ and I.A. TelaI.Aet al., $2015^{[20]}$ which reported more females being infected than males. The difference in result could possibly arose from the genetic makeup of individuals and qualitative and/or quantitative variation in structure and chemical composition of the receptor sites on the erythrocytes membrane of the various other groups that may play an important role in determining susceptibility

This discrepancy in results of different reports could possibly be due to mutation in the genetic mechanism that confers blood groups some protection against the attack of the malaria parasite. Limitation may be due to small sample size that may affectthe distribution of ABO, Variation in location and the time of infection is another factor that might have affected the blood group genetic expression, also geographical distribution has important role in blood groups and their effect with malaria parasite.

\section{Conclusion}

The findings indicate that most frequent blood group in patient group was $\mathrm{A}$, followed by $\mathrm{O}, \mathrm{B}$, and at last $\mathrm{AB}$, the males were significantly more affected by malaria than females and blood group $\mathrm{B}$ is the more susceptible to infection with malaria than other blood group with odd ratio 1.49.

\section{Acknowledgments}

The authors would like to thank all the participants who were enrolled in this study.

\section{References}

[1]. Tekeste Z, Petros B: The ABO blood group and Plasmodium falciparum malaria in Awash, Metehara and Ziway areas, Ethiopia. Malar J. 2010, 9: 280-310.

[2]. WHO. Malaria situation. Weekly epidemiological record. 2015; 45(90):609-616.

[3]. Malik EM, Ahmed ES, Elkhalifa SM, Hussein MA andSulieman AM. Stratification of Khartoum urban area by the risk of malaria transmission. East Mediterranean Health Journal 2003; 9:559-569.

[4]. Nourein AB, Abass MA, Nugud AH, El Hassan I and Snow R. Identifying residual foci of Plasmodium falciparum infections for malaria elimination the urban context of Khartoum, Sudan. PLOS ONE 2011; 6:16948.

[5]. Greenwell P. Blood group antigens: molecules seeking a function? Glycoconj J. 1997; 14(2):159-173

[6]. Frattali A, Spitalnik SL. Blood Group Antigens as Receptors for Pathogens. In: Blancher A, Klein J,Socha WW, eds. Molecular Biology and Evolution of Blood Group and MHC Antigens in Primates.Heidelberg: Springer. 1997:268-304.

[7]. Moulds JM, Moulds JJ. Blood group associations with parasites, bacteria, and viruses. Transfusion Med Rev. 2000; 14:302-311.

[8]. Tursen U, Tiftik EN, Unal S, Gunduz O, Kaya TI, Camdeviren H, et al. Relationship between ABO blood groups and skin cancers. Dermatol Online J. 2005; 11:44.

[9]. Martin SK, Miller LH, Hicks CU, David WA, Ugbode C, Deane M: Frequency of blood group antigens in Nigerian children with falciparum malaria. Trans R Soc Trop Med Hyg. 1979, 73: 216-218. 
[10]. Beiguelman B, Alves FP, Moura MM, Engracia V, Nunes AC, Heckmann MI, et al. The association of genetic markers and malaria infection in the Brazilian Western Amazonian Region. Mem Inst Oswaldo Cruz.2003; 98:455-460.

[11]. Fischer PR, Boone P. Short report: severe malaria associated with blood group. Am J Trop Med Hyg.1998; 58:122-123.

[12]. Pathirana SL, Alles HK, Bandara S, Phone-Kyaw M, Perera MK, Wickremasinghe AR, et al. ABO-blood-group types and protection against severe, Plasmodium falciparum malaria. Ann Trop Med Parasitol.2005; 99:119-124.

[13]. Athreya BH, Coriell LL. Relation of blood groups to infection: I.Asurvey and review of data suggesting possible relationship between malaria and blood groups.Am J Epidemiol. 1967;86:292-304

[14]. Singh N, Shukla MM, Uniyal VP, Sharma VP. ABO blood groups among malaria cases from district Mandla, Madhya Pradesh. Indian J Malariol 1995; 32: 59-63.

[15]. Fry AE, Griffiths MJ, Auburn S, Diakite M, Forton JT, Green A, et al. Common variation in the ABO glycosyltransferase is associated with susceptibility to severe Plasmodium falciparum malaria. Hum Mol Genet 2008; 17: 567-576.

[16]. Zerihun T, Degarege A, Erko B. Association of ABO blood group and Plasmodium falciparum malaria in Dore Bafeno Area, SouthernEthiopia. Asian Pac J Trop Biomed. 2011;1(4):289-294.

[17]. Singh N, Shukla MM, Uniyal VP, Sharma VP. ABO group among malaria cases Anstee DJ. The relationship between blood groups and disease. Blood 2010; 115: 4635-43.

[18]. Mourant AE, Kopec AC, Domaniewska-Sobczak K. The distribution of the human blood groups and other polymorphisms. London: Oxford University Press; 1976.

[19]. Bonilla, E.; and Rodriguez, A. Determin-ing malaria effects in rural Colombia. Social Science and Medicine. 1993; 37(9): 1,109-14.

[20]. Vlassoff, C.; and Bonilla, E. Gender-related differences in the impact of tropical diseases on women: what do we know? Journal of Biosocial Science.1994;26(1): 37-53.

[21]. TelaI.A., M.H. Modibbo, L.H. Adamu, M.G. Taura. RA Journal of Applied Research. 2015;1(7): $255-262$. 